\title{
Simple and Practical Aerobic Oxidation of Alcohols Catalyzed by a $\left(\mu\right.$-Oxo)tetraruthenium Cluster ${ }^{*}$
}

\author{
Teruyuki Kondo ${ }^{1 \#}$, Yu Kimura ${ }^{1}$, Takashi Kanda ${ }^{2}$, Daisuke Takagi ${ }^{2}$, Kenji Wada ${ }^{2}$, Akio Toshimitsu ${ }^{3}$ \\ ${ }^{1}$ Advanced Biomedical Engineering Research Unit, Kyoto University, Kyoto, Japan \\ ${ }^{2}$ Department of Energy and Hydrocarbon Chemistry, Graduate School of Engineering, Kyoto University, Kyoto, Japan \\ ${ }^{3}$ Division of Multidisciplinary Chemistry, Institute for Chemical Research, Kyoto University, Kyoto, Japan \\ E-mail:"teruyuki@scl.kyoto-u.ac.jp \\ Received September 19, 2011; revised October 25, 2011; accepted November 4, 2011
}

\begin{abstract}
A ( $\mu$-oxo)tetraruthenium cluster showed high catalytic activity for a simple and practical aerobic oxidation of alcohols to aldehydes and ketones under 1 atm of $\mathrm{O}_{2}$ or air. After the reaction, this cluster catalyst was recovered from the reaction mixture, and we believe that this ( $\mu$-oxo)tetraruthenium cluster acts as an active catalytic species throughout the reaction.
\end{abstract}

Keywords: Ruthenium, Cluster, Catalyst, Aerobic Oxidation, Alcohol

\section{Introduction}

The selective oxidation of primary and secondary alcohols to the corresponding aldehydes and ketones, respecttively, is a ubiquitous and pivotal reaction in organic synthesis and the chemical industry [1,2]. Such oxidation reactions have been performed traditionally with stoichiometric inorganic oxidants, represented by $\mathrm{CrO}_{3}, \mathrm{KMnO}_{4}$, $\mathrm{MnO}_{2}$, and $\mathrm{SeO}_{2}$ [3]. However, these oxidation methods have serious drawbacks, such as their cost and the production of environmentally hazardous/toxic byproducts. From both economic and environmental viewpoints [4], there is an urgent demand for greener, more atom-efficient methods that use $\mathrm{O}_{2}$ and air as readily available terminal and ideal oxidants, and produce only $\mathrm{H}_{2} \mathrm{O}$ as a byproduct. Among the various transition-metal catalysts, much attention has been focused on the ability of ruthenium catalysts, since they have often been used for hydrogenation and transfer hydrogenation reactions [5] as well as dehydrogenation and oxidation reactions [6,7]. In fact, some success has been realized using ruthenium catalysts in alcohol oxidation with $\mathrm{NaIO}_{4}$ [8], tert-butyl hydroperoxide [9,10], chloramine-T [11], amine- $N$-oxide [11], iodosylbenzene [12], $\mathrm{NaBrO}_{3}[13,14]$, benzoquinone/Co(salen) [15-17], $\mathrm{H}_{2} \mathrm{O}_{2}$ [18], and TEMPO [19] as oxidants. However, there are few examples of a ruthenium-catalyzed real aerobic oxidation of alcohols without hydrogen acceptors [20,21]. Most recently, Hill and

*Dedicated to Professor Christian Bruneau on the occasion of his 60th birthday. coworkers reported the ruthenium-catalyzed practical aerobic oxidation of alcohols in a continuous-flow reactor [22].

We have been interested in ruthenium chemistry, and have successfully synthesized many novel low-valent ruthenium complexes $[23,24]$, which can be used as highly efficient catalysts for characteristic organic synthesis $[25,26]$. In addition, we have recently succeeded in the synthesis of a novel and isolable ( $\mu$-oxo)tetraruthenium cluster (2) [27] by an unusual reaction of a zero-valent ruthenium complex, $\operatorname{Ru}\left(\eta^{6}-\cot \right)\left(\eta^{2}-\mathrm{dmfm}\right)_{2}(\mathbf{1})[\cot =1,3$, 5-cyclooctatriene, $\mathrm{dmfm}=$ dimethyl fumarate] [28], with $\mathrm{H}_{2} \mathrm{O}$ (Scheme 1).

Here, we report that this novel ( $\mu$-oxo)tetraruthenium cluster (2) efficiently catalyzes a simple, practical, and selective oxidation of primary and secondary alcohols to the corresponding aldehydes and ketones, respectively, under $1 \mathrm{~atm}$ of $\mathrm{O}_{2}$ or air.

\section{Results and Discussion}

Benzyl alcohol was smoothly oxidized in $N, N$-dimethylacetamide (DMA) at $80^{\circ} \mathrm{C}$ for $20 \mathrm{~h}$ under $1 \mathrm{~atm}$ of $\mathrm{O}_{2}$ (balloon) to give benzaldehyde in 95\% yield (Scheme 2). Neither benzoic acid nor acetal of benzaldehyde was obtained at all.

Among the solvents examined, toluene also gave the good results, and benzaldehyde was obtained in $94 \%$ yield, while in dioxane, propionitrile, and pyridine the conversion of benzyl alcohol decreased drastically to 

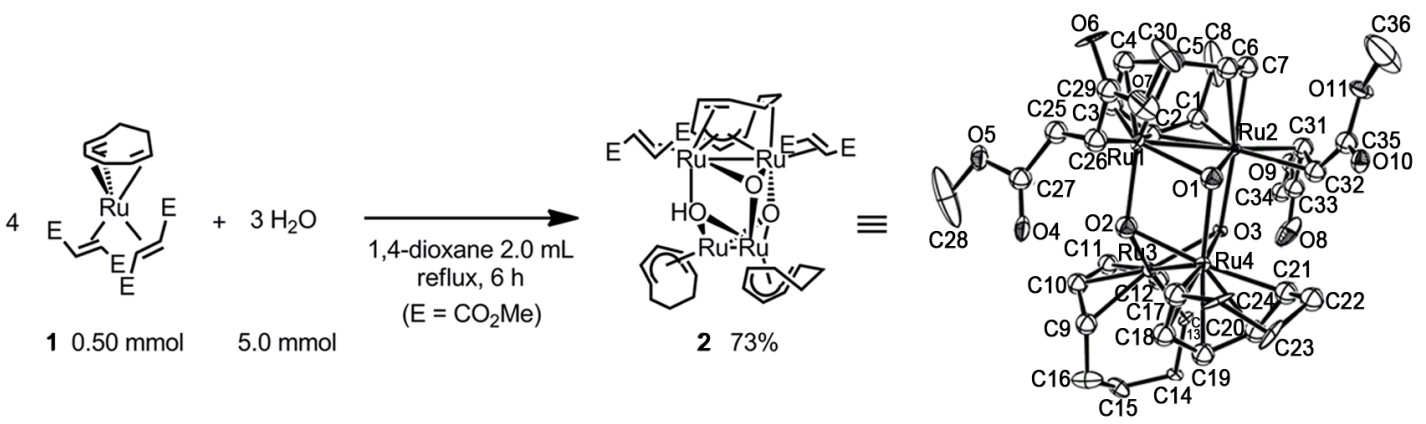

Scheme 1. Synthesis of 2 by the reaction of 1 with $\mathrm{H}_{2} \mathrm{O}$.

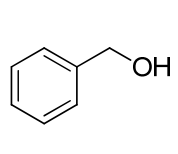

$1.0 \mathrm{mmol}$
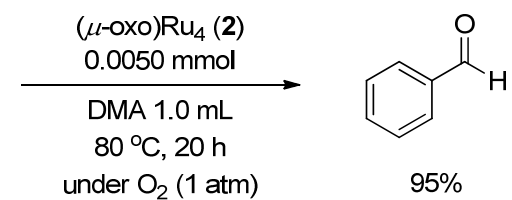

Scheme 2. Aerobic oxidation of benzyl alcohol to benzaldehyde catalyzed by 2 .

give benzaldehyde in only $33 \%, 7 \%$, and $2 \%$ yield, respectively.

Thus, the oxidation of primary alcohols bearing heteroaromatic rings, such as 2-thiophenemethanol and 2-pyridinemethanol, proceeded at an elevated temperature of $110^{\circ} \mathrm{C}$ (Table 1, Entries 3 and 4) to give the corresponding aldehydes in good to high yields, while with aliphatic alcohols, such as 1-octanol and cyclohexanemethanol, the yield of the desired aldehydes decreased somewhat due to the formation of carboxylic acids (overoxidation) and esters (Tischenko-type-reaction) (Entries 5 and 6).

Secondary alcohols were also converted into the corresponding ketones when the reaction was carried out at $130^{\circ} \mathrm{C}$ (Table 2). For example, benzophenone was obtained quantitatively by the aerobic oxidation of diphenylmethanol (Entry 1). Methyl 2-hydroxy-2-phenylacetate was also converted into methyl 2-oxo-2-phenylacetate in $81 \%$ yield (Entry 3 ). In all reactions, no ketals were formed at all.

The present catalyst system is highly active, and the oxidation of benzyl alcohol proceeded smoothly at 110 ${ }^{\circ} \mathrm{C}$ for $48 \mathrm{~h}$ under $1 \mathrm{~atm}$ of air (balloon) to give benzaldehyde in $87 \%$ yield with $95 \%$ selectivity (Scheme 3), while benzaldehyde was obtained in only $26 \%$ yield under an argon atmosphere ${ }^{\text {a }}$. Diphenylmethanol also gave benzophenone in $93 \%$ yield under $1 \mathrm{~atm}$ of air.

After the reactions, ( $\mu$-oxo)tetraruthenium cluster (2) was recovered in $20 \%$ yield by simple column chromatography, which was confirmed by ${ }^{1} \mathrm{H}$ NMR [27]. In

${ }^{a}$ Under an argon atmosphere, catalytic dehydrogenation of benzyl alcohol occurred to give benzaldehyde in $26 \%$ yield together with the formation of $\mathrm{H}_{2}(0.20 \mathrm{mmol})$, which was confirmed by a careful GC analysis of the gas phase.
Table 1. Aerobic oxidation of primary alcohols to aldehydes catalyzed by $2^{\mathrm{a}}$.

Entry

a (2) $(0.0050 \mathrm{mmol})$, alcohol $(1.0 \mathrm{mmol})$, DMA $(1.0 \mathrm{~mL})$ for $20 \mathrm{~h}$ under an $\mathrm{O}_{2}$ (1 atm, balloon). ${ }^{b} \mathrm{GLC}$ yield (isolated yield). ${ }^{\mathrm{c} O c t y l}$ octanoate (12\%) was generated together with a small amount of octanoic acid (below $10 \%$ ). ${ }^{\mathrm{d}}$ Cyclohexanecarboxylic acid (21\%), and cyclohexylmethyl cyclohexanecarboxylate $(15 \%)$ were generated.

Table 2. Aerobic oxidation of secondary alcohols to ketones catalyzed by $2^{\mathrm{a}}$.

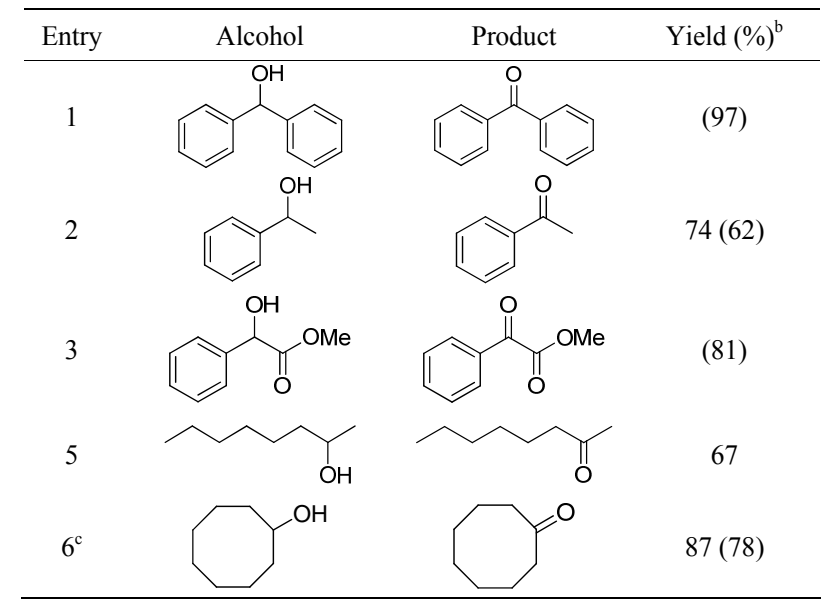

${ }^{\mathrm{a}}(2)(0.0050 \mathrm{mmol})$, alcohol $(1.0 \mathrm{mmol})$, DMA $(1.0 \mathrm{~mL})$ at $130{ }^{\circ} \mathrm{C}$ for $20 \mathrm{~h}$ under an $\mathrm{O}_{2}$ (1 atm, balloon). ${ }^{b} \mathrm{GLC}$ yield (isolated yield). ${ }^{\mathrm{c}} \mathrm{At} 160^{\circ} \mathrm{C}$. 

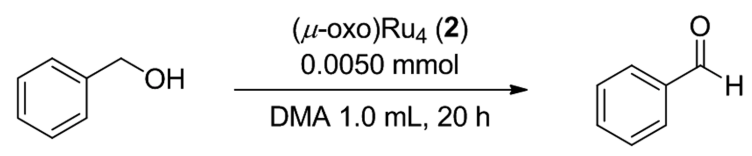

$1.0 \mathrm{mmol}$

Scheme 3. Oxidation of benzyl alcohol to benzaldehyde under $\mathrm{O}_{2}$, air and Ar atmosphere.

addition, mononuclear $\mathrm{Ru}\left(\eta^{6}-\cot \right)\left(\eta^{2}-\mathrm{dmfm}\right)_{2}(\mathbf{1})$, which is the starting material for the synthesis of ( $\mu$-oxo) tetraruthenium cluster (2), showed no catalytic activity in either the absence or presence of a small amount of $\mathrm{H}_{2} \mathrm{O}$. No induction period was observed, and benzaldehyde was generated from the initial stage of the reaction (Figure 1).

Based on the results described above, we believe that a ( $\mu$-oxo)tetraruthenium cluster (2) acts as an active catalytic species throughout the reaction [29,30]. There are two possible catalytic cycles to be considered (A and B), which are illustrated in Scheme 4. In catalytic cycle A, the reaction starts with the alcoholysis of a hydroxo$\mathrm{Ru}$ (II) bond in $\mathbf{2}$ with an alcohol to give an (alkoxo)Ru(II) cluster together with $\mathrm{H}_{2} \mathrm{O}$. Oxidation of the alkoxoattached ruthenium atom with $\mathrm{O}_{2}$ then occurs to give a cluster containing an (alkoxo)(peroxo)Ru(III) part, followed by $\beta$-hydrogen elimination from an alkoxo functionality and hydrogen transfer to a peroxyo group to give a (hydroperoxo) $\mathrm{Ru}(\mathrm{II})$ cluster and the corresponding aldehyde. Final alcoholysis of a (hydroperoxo) Ru(II) cluster would give $\mathrm{H}_{2} \mathrm{O}_{2}$ with the regeneration of an (alkoxo) $\mathrm{Ru}(\mathrm{II}$ ) cluster. In the other possible catalytic cycle B, a ( $\mu$-oxo)tetraruthenium cluster (2) is first converted into an (alkoxo)(hydroxo)Ru(II) cluster by addition of an alcohol to

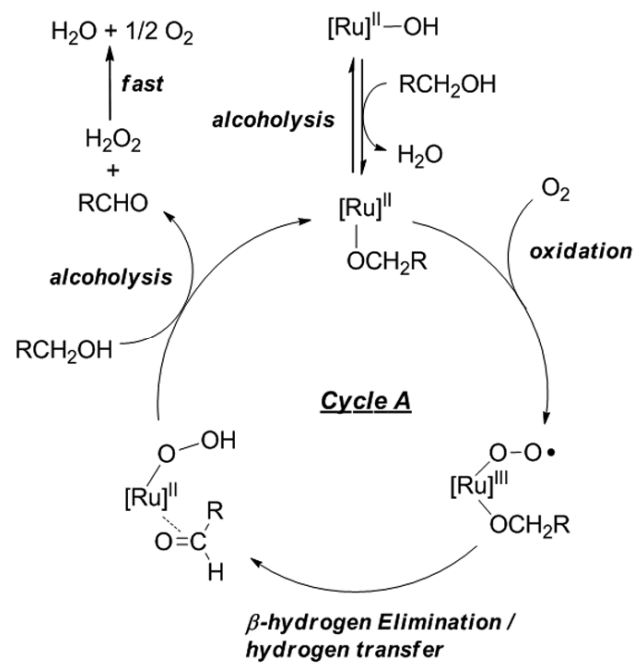

a bridging oxo-Ru bond. Subsequent $\beta$-hydrogen elimination releases an aldehyde, and a (hydrido)(hydroxo) $\mathrm{Ru}(\mathrm{II})$ cluster is formed. Insertion of $\mathrm{O}_{2}$ into a hydrido-Ru bond gives a (hydroperoxo)(hydroxo) $\mathrm{Ru}(\mathrm{II})$ cluster, and subsequent hydrogen abstraction from a hydroxo functionality gives $\mathrm{H}_{2} \mathrm{O}_{2}$ with the regeneration of 2 . After the reaction, no peroxide was detected in the reaction mixture by a peroxide test (see Experimental), and we consider that $\mathrm{H}_{2} \mathrm{O}_{2}$ is decomposed immediately to $\mathrm{H}_{2} \mathrm{O}$ and $\mathrm{O}_{2}$ under the present reaction conditions.

Although there is not yet much evidence for full consideration and discussion of the mechanism, the recent study on the mechanism of ruthenium-catalyzed alcohol oxidation, in which the active [Ru]-OH species could be generated, supports the mechanism according to the catalytic cycle $\mathrm{B}[19,31,32]$, and the real oxidant in the present reaction is $\mathrm{O}_{2}$, not $\mathrm{H}_{2} \mathrm{O}_{2}$. A further mechanistic study including observation of KIE (Kinetic Isotope Effect) for alcohols is now in progress.

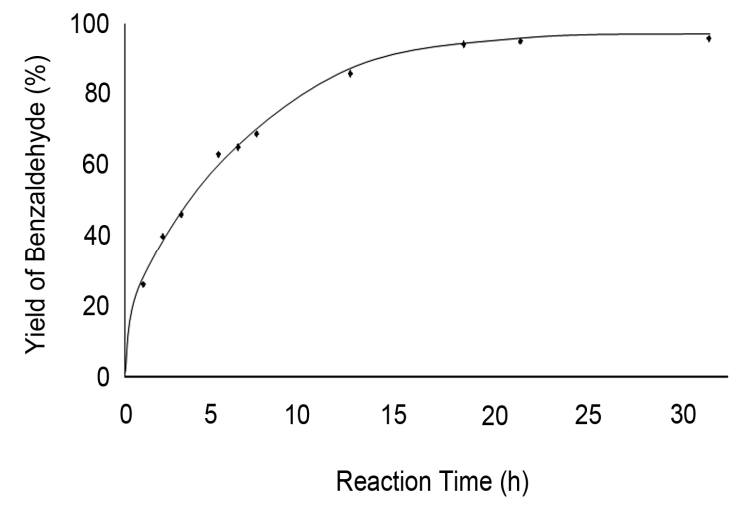

Figure 1. Time-course of aerobic oxidation of benzyl alcohol to benzaldehyde catalyzed by 2 .

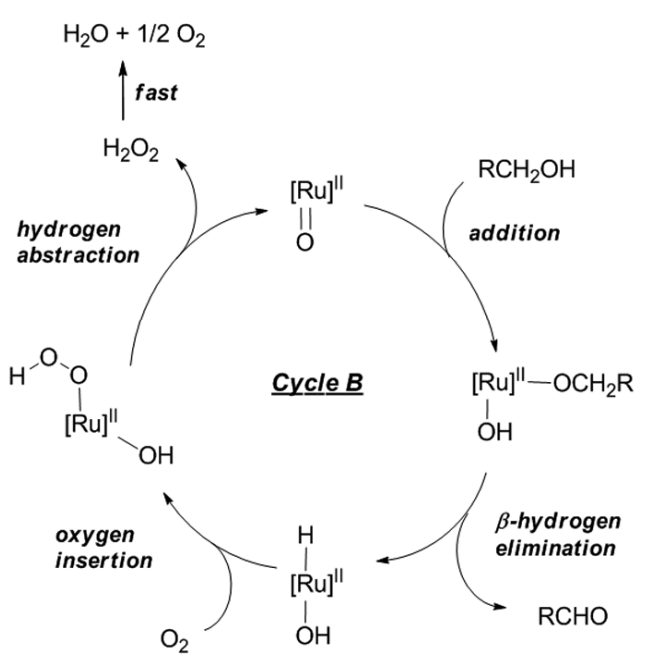

Scheme 4. Possible catalytic cycles for $(\mu$-oxo $) \mathrm{Ru}_{4}(2)$-catalyzed aerobic oxidation of primary alcohols to aldehydes. 


\section{Experimental}

\subsection{Materials}

Alcohols were obtained commercially and purified before use by standard procedures. Anhydrous DMA and dioxane were obtained commercially and used as received. Anhydrous toluene, $\mathrm{THF}$, and $\mathrm{CH}_{2} \mathrm{Cl}_{2}$ were obtained by filtration through a drying column on a Glass Contour system [33], and used after bubbling with argon. $\mathrm{Ru}\left(\eta^{6}-\cot \right)-$ $\left(\eta^{2}-\mathrm{dmfm}\right)_{2}(\mathbf{1})$ and $(\mu$-oxo)tetraruthenium cluster (2) were prepared as described in the literature $[27,28]$. Quantofix ${ }^{\circledR}$ peroxide test paper was used to detect $\mathrm{H}_{2} \mathrm{O}_{2}$.

\subsection{General}

GLC analyses were carried out on a Shimadzu GC14BPF (FID) gas chromatograph equipped with a glass column $(2.8 \mathrm{~mm}$ i.d. $\times 3 \mathrm{~m})$ packed with Silicone OV-17 (2\% on Chromosorb W(AW-DMCS), 60 mesh - 80 mesh). The formation of hydrogen was analyzed carefully by a Shimadzu 8AIT (TCD) gas chromatograph equipped with a stainless column $(3.0 \mathrm{~mm}$ i.d. $\times 2 \mathrm{~m})$ packed with MS-5A. GC/MS analyses were performed using a Shimadzu Parvum2 mass spectrometer connected to a Shimadzu GC-2010 gas chromatograph [column: J \& W Scientific capillary column DB-1, $0.25 \mathrm{~mm}$ i.d. $\times 25 \mathrm{~m}$ (film thickness $0.25 \mu \mathrm{m}$ )]. ${ }^{1} \mathrm{H}-\mathrm{NMR}$ spectra were recorded at $400 \mathrm{MHz}$, and ${ }^{13} \mathrm{C}-\mathrm{NMR}$ spectra were recorded at $100 \mathrm{MHz}$. Samples were analyzed in $\mathrm{CDCl}_{3}$, and the chemical shift values are expressed relative to $\mathrm{Me}_{4} \mathrm{Si}$ as an internal standard. IR spectra were obtained on a JASCO FT/IR-4200 spectrometer.

\subsection{General Procedure for the ( $\mu$-Oxo)Tetraruthenium Cluster-Catalyzed Oxidation of Alcohols to Aldehydes and Ketones}

A mixture of alcohol $(1.0 \mathrm{mmol}),(\mu$-oxo)tetraruthenium cluster (2) (0.0050 mmol), and $N, N$-dimethylacetamide $(1.0 \mathrm{~mL})$ was placed in a $20 \mathrm{~mL}$ Pyrex flask equipped with a magnetic stirring bar and a reflux condenser under a flow of argon. The reaction vessel was then connected to a balloon containing $\mathrm{O}_{2}$ or air (1 atm). The reaction was carried out at $80^{\circ} \mathrm{C}-110{ }^{\circ} \mathrm{C}$ (for primary alcohols) or $130{ }^{\circ} \mathrm{C}$ (for secondary alcohols) for $20 \mathrm{~h}$ with stirring. After being allowed to cool, the reaction mixture was analyzed by GLC. The products were isolated by Kugelrohr distillation, if necessary, followed by silica gel column chromatography (KANTO CHEMICAL, Silica Gel 60N (spherical, neutral), $40 \mu \mathrm{m}$ - $50 \mu \mathrm{m}$, eluent: he$\mathrm{xane} / \mathrm{EtOAc}=8 / 1)$, and identified by comparing the spe- ctral $\left({ }^{1} \mathrm{H}\right.$ and ${ }^{13} \mathrm{C}$ NMR spectra [34]) and analytical data with those of authentic samples.

\section{Conclusions}

One of the major goals of catalysis today is the design of environmentally benign and highly atom-efficient processes to replace traditional waste-forming reactions, including some of the most fundamental synthetic methods. Our method for the catalytic oxidation of alcohols to aldehydes and ketones can be used with a wide range of alcohols, is highly atom-efficient, and is particularly convenient with respect to a simple operation under $1 \mathrm{~atm}$ of $\mathrm{O}_{2}$ or air as the real oxidants.

\section{Acknowledgements}

This work was supported in part by a Grant-in-Aid for Challenging Exploratory Research (No. 22655025) from the Japan Society for the Promotion of Science (JSPS). T.K. acknowledges financial support from the Asahi Glass Foundation and the Yazaki Memorial Foundation for Science and Technology. This research was conducted in part at the Advanced Research Institute (Research Project of Engineering for Sustainable Environment), Katsura-Int'tech Center, Graduate School of Engineering, Kyoto University.

\section{References}

[1] I. W. C. E. Arends and R. A. Sheldon, "Modern Oxidation of Alcohols Using Environmentally Benign Oxidants," In: J.-E. Bäckvall, Ed., Modern Oxidation Methods, Wiley-VCH, Weinheim, 2004, pp. 83-118.

[2] I. W. C. E. Arends and R. A. Sheldon, "Modern Oxidation of Alcohols Using Environmentally Benign Oxidants," In: J.-E. Bäckvall, Ed., Modern Oxidation Methods, 2nd Edition, Wiley-VCH, Weinheim, 2010, pp. 147185. doi:10.1002/9783527632039.ch5

[3] M. B. Smith and J. March, "March's Advanced Organic Chemistry: Reactions, Mechanisms, and Structure," 6th Edition, John Wiley \& Sons, Hoboken, 2007, pp. 17031786.

[4] P. T. Anastas, "Green Catalysis," Wiley-VCH, Weinheim, 2009.

[5] M. Kitamura and R. Noyori, "Hydrogenation and Transfer Hydrogenation," In: S.-I. Murahashi, Ed., Ruthenium in Organic Synthesis, Wiley-VCH, Weinheim, 2004, pp. 3-52.

[6] S.-I. Murahashi and N. Komiya, "Oxidation Reactions," In: S. -I. Murahashi, Ed., Ruthenium in Organic Synthesis, Wiley-VCH, Weinheim, 2004, pp. 53-93. doi:10.1002/3527603832

[7] I. W. C. E. Arends, T. Kodama and R. A. Sheldon, "Oxi- 
dation Using Ruthenium Catalysts," In: C. Bruneau and P. H. Dixneuf, Eds., Ruthenium Catalysts and Fine Chemistry, Springer, Berlin, 2004, pp. 277-320.

[8] W. S. Trahanovsky, "Oxidation in Organic Chemistry," Academic Press, Cleveland, 1973.

[9] Y. Tsuji, T. Ohta, T. Ido, H. Minbu and Y. Watanabe, "Ruthenium-Catalyzed Oxidation of Alcohols and Catechols Using t-Butyl Hydroperoxide," Journal of Organometallic Chemistry, Vol. 270, No. 3, 1984, pp. 333-341. doi:10.1016/0022-328X(84)80381-2

[10] S.-I. Murahashi and T. Naota, "Ruthenium-Catalyzed Oxidations for Selective Syntheses of Ketones and Acyl Cyanides. Selective Acylation of Amino Compounds with Acyl Cyanides," Synthesis, Vol. 50, No. 4, 1993, pp. 433-440. doi:10.1055/s-1993-25877

[11] K. B. Sharpless, K. Akashi and K. Oshima, "RutheniumCatalyzed Oxidation of Alcohols to Aldehydes and Ketones by Amine-N-Oxides," Tetrahedron Letters, Vol. 17, No. 29, 1976, pp. 2503-2506. doi:10.1016/S0040-4039(00)78130-5

[12] P. Müller and J. Gody, "Catalyzed Oxidation of Alcohols and Aldehydes with Iodosylbenzene," Tetrahedron Letters, Vol. 22, No. 25, 1981, pp. 2361-2364. doi:10.1016/S0040-4039(01)82906-3

[13] Y. Yamamoto, H. Suzuki and Y. Moro-oka, "RutheniumCatalyzed Oxidation of Alcohols with Sodium Bromate," Tetrahedron Letters, Vol. 26, No. 17, 1985, pp. 21072108. doi:10.1016/S0040-4039(00)94791-9

[14] S. Kanemoto, H. Tomioka, K. Oshima and H. Nozaki, "Cerium or Ruthenium-Catalysed Oxidation of Alcohols to Carbonyl Compounds by means of Sodium Bromate," Bulletin of the Chemical Society of Japan, Vol. 59, No. 1, 1986, pp. 105-108. doi:10.1246/bcsj.59.105

[15] J.-E. Bäckvall, R. L. Chowdhury and U. Karisson, "Ruthenium-Catalyzed Aerobic Oxidation of Alcohols via Multistep Electron Transfer," Journal of the Chemical Society, Chemical Communications, No. 7, 1991, pp. 473-475. doi:10.1039/C39910000473

[16] C. Csjernyik, A. H. Éll, L. Fadini, B. Pugin and J.-E. Bäckvall, "Efficient Ruthenium-Catalyzed Aerobic Oxidation of Alcohols Using a Biomimetic Coupled Catalytic System," Journal of Organic Chemistry, Vol. 67, No. 5, 2002, pp. 1657-1662. doi:10.1021/jo0163750

[17] E. V. Johnston, E. A. Karlsson, L.-H. Tran, B. Åkermark and J.-E. Bäckvall, "Efficient Aerobic Ruthenium-Catalyzed Oxidation of Secondary Alcohols by the use of a Hybrid Electron Transfer Catalyst," European Journal of Organic Chemistry, No. 10, 2010, pp. 1971-1976. doi:10.1002/ejoc. 201000033

[18] F. Shi, M. K. Tse and M. Beller, "A Novel Environmentally Benign Method for the Selective Oxidation of Alcohols to Aldehydes and Ketones," Chemistry, an Asian Journal, Vol. 2, No. 3, 2007, pp. 411-415. doi:10.1002/asia.200600383

[19] A. Dijksman, A. Marino-González, A. M. I. Payeras, I. W. C. E. Arends and R. A. Sheldon, "Efficient and Selective Aerobic Oxidation of Alcohols into Aldehydes and Ke- tones Using Ruthenium/TEMPO as the Catalytic System," Journal of the American Chemical Society, Vol. 123, No. 28, 2001, pp. 6826-6833. doi:10.1021/ja0103804

[20] C. Bilgrien, S. Davis and R. S. Drago, "The Selective Oxidation of Primary Alcohols to Aldehydes by $\mathrm{O}_{2}$ Employing a Trinuclear Ruthenium Carboxylate Catalyst," Journal of the American Chemical Society, Vol. 109, No. 12, 1987, pp. 3786-3787. doi:10.1021/ja00246a049

[21] I. E. Markó, P. R. Giles, M. Tsukazaki, I. Chellé-Regnaut, C. J. Urch and S. M. Brown, "Efficient, Aerobic, Ruthenium-Catalyzed Oxidation of Alcohols into Aldehydes and Ketones," Journal of the American Chemical Society, Vol. 119, No. 51, 1997, 12661-12662. doi: $10.1021 / \mathrm{ja} 973227 \mathrm{~b}$

[22] N. Zotova, K. Hellgardt, G. H. Kelsall, A. S. Jessiman and K. K. Hill, "Catalysis in Flow: The Practical and Selective Aerobic Oxidation of Alcohols to Aldehydes and Ketones," Green Chemistry, Vol. 12, No. 12, 2010, 2157 2163. doi:10.1039/c0gc00493f

[23] T. Mitsudo, Y. Ura and T. Kondo, "Chemistry of Ru ( $\eta^{6}-$ 1,3,5-cyclooctatriene $)\left(\eta^{2} \text {-dimethyl fumarate }\right)_{2}$, " Chemical Record, Vol. 6, No. 3, 2006, pp. 107-116. doi:10.1002/tcr.20076

[24] T. Mitsudo, Y. Ura and T. Kondo, "Chemistry of a Novel Zerovalent Ruthenium $\pi$-Acidic Alkene Complex, $\mathrm{Ru}\left(\eta^{6}\right.$ 1,3,5-cyclooctatriene $)\left(\eta^{2} \text {-dimethyl fumarate }\right)_{2}$, , Proceedings of the Japan Academy, Series B, Vol. 83, No. 3, 2007, pp. 65-76. doi:10.2183/pjab.83.65

[25] T. Kondo, "On Inventing Catalytic Reactions via Ruthenaor Rhodacyclic Intermediates for Atom Economy," Synlett, No. 5, 2008, pp. 629-644. doi:10.1055/s-2008-1042807

[26] T. Kondo, "New Catalytic Performances of Ruthenium and Rhodium Complexes Directed toward Organic Synthesis with High Atom Efficiency," Bulletin of the Chemical Society of Japan, Vol. 84, No. 5, 2011, pp. 441-458. doi:10.1246/bcsj.20110019

[27] T. Kondo, F. Tsunawaki, T. Suzuki, Y. Ura, K. Wada, S. Yamaguchi, H. Masuda, K. Yoza, M. Shiro and T. Mitsudo, "Synthesis and Characterization of a Novel $\left(\mu_{3}\right.$ Oxo)tetraruthenium Cluster," Journal of Organometallic Chemistry, Vol. 692, No. 1-3, 2007, pp. 530-535. doi:10.1016/j.jorganchem.2006.08.062

[28] T. Mitsudo, T. Suzuki, S.-W. Zhang, D. Imai, K.i Fujita, T. Manabe, M. Shiotsuki, Y. Watanabe, K. Wada and T. Kondo, "Novel Ruthenium Complex-Catalyzed Dimerization of 2,5-Norbornadiene to Pentacyclo $\left[6.6 .0^{2,6} \cdot 0^{3,13}\right.$. $0^{10,14}$ tetradeca-4,11-diene Involving Carbon-Carbon Bond Cleavage," Journal of the American Chemical Society, Vol. 121, No. 9, 1999, pp. 1839-1850. doi:10.1021/ja9835741

[29] M. S. Thompson and T. J. Meyer, "Mechanisms of Oxidation of 2-Propanol by Polypyridyl Complexes of Ruthenium (III) and Ruthenium (IV)," Journal of the American Chemical Society, Vol. 104, No. 15, 1982, pp. 41064115. doi:10.1021/ja00379a011

[30] C. S. Yi, T. N. Zeczycki and I. A. Guzei, "Highly Coop- 
erative Tetrametallic Ruthenium- $\mu$-Oxo- $\mu$-Hydroxo Catalyst for the Alcohol Oxidation Reaction," Organometallics, Vol. 25, No. 4, 2006, pp. 1047-1051.

doi:10.1021/om0510674

[31] A. M. Khenkin, L. J. W. Shimon and R. Neumann, Preparation and Characterization of New Ruthenium and Osmium Containing Polyoxo-metalates, $\left[\mathrm{M}(\mathrm{DMSO})_{3} \mathrm{M}_{7} \mathrm{O}_{24}\right]^{4-}$ $(\mathrm{M}=\mathrm{Ru}(\mathrm{II}), \mathrm{Os}(\mathrm{II}))$, and Their Use as Catalysts for the Aerobic Oxidation of Alcohols," Inorganic Chemistry, Vol. 42, No. 10, 2003, pp. 3331-3339. doi:10.1021/ic026003p

[32] F. Nikaidou, H. Ushiyama, K. Yamaguchi, K. Yamashita and N. Mizuno, "Theoretical and Experimental Studies on Reaction Mechanism for Aerobic Alcohol Oxidation by Supported Ruthenium Hydroxide Catalysts," Journal of Physical Chemistry C, Vol. 114, No. 24, 2010, pp. 10873-10880. doi:10.1021/jp101692j

[33] A. B. Pangborn, M. A. Giardello, R. H. Grubbs, R. K. Rosen and F. J. Timmers, "Safe and Convenient Procedure for Solvent Purification," Organometallics, Vol. 15, No. 5, 1996, pp. 1518-1520. doi:10.1021/om9503712

[34] C. Pouchert, "Aldrich Library of ${ }^{13} \mathrm{C}$ and ${ }^{1} \mathrm{H}$ FT-NMR Spectra," John Wiley \& Sons, Hoboken, 1993. 